\title{
Development and functional properties of low-cost complementary food
}

\author{
Getachew Addis ${ }^{1 *}$, Vasudeva Singh ${ }^{2}$, Vishwas Pratape $^{2}$, Alok Srivastava $^{2}$, Lalitha Gowda ${ }^{2}$, \\ Madhavan Asha ${ }^{2}$ and Sila Bhattacharya ${ }^{2}$ \\ ${ }^{1}$ Ethiopian Health and Nutrition Research Institute, P.O. Box 1242, Addis Ababa, Ethiopia. \\ ${ }^{2}$ Central Food Technological Research Institute, Mysore-570 020, India.
}

Accepted 18 July, 2013

\begin{abstract}
Development of complementary food that contains adequate nutrients at affordable costs is quite a challenge for developing countries. The traditional complementary foods are viscous and lack essential nutrients. The objective of this study was to formulate and evaluate the physicochemical properties and acceptability of a complementary food. A preliminary study was conducted to select the appropriate processing method and estimate the nutritional composition of the ingredients. Accordingly, the complementary food was formulated from processed sorghum, pigeon pea, soybean along with skimmed milk and sucrose in the proportion of 65:15:10:5:5. The blend (95\%) was mixed with malted finger millet $(5 \%)$. Functional properties, sensory attributes, amino acid composition and trypsin inhibitor activity (TIA) of the product were evaluated. The product was easily dispersed in warm water and the reconstitution had a smooth and homogeneous consistency. The dry basis composition of the product was $14.4 \%$ digestible protein, $59 \%$ digestible starch, $4.2 \%$ fat, $12.8 \%$ total dietary fiber and $2.4 \%$ total minerals. Calcium, magnesium, iron and zinc level were 145.2, 94.5, 6.0 and $2.0 \mathrm{mg}$ per $100 \mathrm{~g}$ dry basis, respectively. TIA in the product was inactivated to trace. Physicochemical properties of the formulated product were within the acceptable standard for children aged between 6 and 24 months. The newly developed complementary food may contribute to alleviating child malnutrition.
\end{abstract}

Key words: Cereals, pulses, skimmed milk, viscosity, complementary food.

\section{INTRODUCTION}

The major risk factors associated with infant and early childhood mortality and morbidity are poor infant feeding practices as well as childhood and maternal undernutrition (WHO, 2009). Unlike developed countries where there are many children affected by obesity, most children in developing countries such as sub-Saharan Africa and Southeast Asia are conversely affected by lack of food or inadequate supply of energy and nutrients. Malnutrition is one of the major problems facing infants and young children of developing countries. Following a study conducted for 12 consecutive years (1980 to 1992), WHO has reported that more than one third of children aged less than five years in developing countries suffer from chronic malnutrition (de Onis et al., 1997). UNICEF (2009) indicated that more than 4.6 million annual deaths of children occur in Africa. In Ethiopia, 47 and $11 \%$ of under five children are stunted and wasted, respectively (Central Statistical Agency and ORC Macro, 2006). A higher rate of under five mortality due to protein-energy malnutrition is also reported in Ethiopia (Government of the Federal Democratic of Ethiopia, 2008) and Sudan (Asma et al., 2006). Furthermore, pocket studies on micronutrient deficiencies indicate higher prevalence of iron and zinc deficiency especially in young children 
(Getahun et al., 2001). The situation is similar with Asian countries like India (Thathola and Srivastava, 2002). Appropriate complementary feeding of the infant and adequate nutrition are among the crucial measures required to avert infant and early childhood deaths (UNICEF, 2009).

In developing countries, children are mostly weaned on starchy, bulky gruels which are characterized by both low energy and low nutrient density. The traditional complementary food is mainly based on starch staples such as rice, sorghum, maize and wheat. Although the cereals contain sufficient sulfur containing amino acids (methionine and cysteine), which are limiting in pulses, they are deficient in lysine, which is rich in pulses (Gopalan et al., 1989). The unavailability of nutritious food and the high cost of commercial complementary foods and animal protein are the main causes of protein-energy malnutrition in children in the developing countries. Therefore, developing nutrient-dense, safe, affordable and accessible complementary food from locally produced ingredients using household or small to medium scale production technologies has been strongly recommended as a viable and sustainable approach to address the problem of malnutrition (WHO, 1998). The main objective of the present study was therefore to formulate a reduced bulk nutrient-dense complementary food for children, characterize the food and study the nutritional and sensory acceptability of the product.

\section{MATERIALS AND METHODS}

\section{Selection and source of ingredients}

Sorghum, soybean and pigeon pea were strategically selected to meet $\mathrm{FAO} / \mathrm{WHO} / \mathrm{UNU}$ complementary food quality requirements of essential amino acids (FAO/WHO/UNU, 1985). Sorghum (Sorghum bicolor L.), skimmed milk and sucrose were purchased from Mysore, India. Soybean (Glycine max L.) and pigeon pea (Cajanus cajan L.) were procured from the University of Agricultural Sciences, Bangalore, India. Finger millet (Eleusine coracana L.) malt was obtained from M/s. Christy Food Grains, Tamil Nadu. The raw materials were cleaned to free from extraneous matter and damaged grains.

\section{Processing of ingredients for complementary food formulation}

\section{Sorghum}

Grains were conditioned (equilibrated) to different moisture content ranging from $\sim 12$ to $20 \%$ and kept in tightly closed containers for 14 $\mathrm{h}$ at room temperature with occasional mixing. Treated grains were popped in a laboratory popcorn maker at $260^{\circ} \mathrm{C}$ for $30 \mathrm{~s}$. Percentages of popped material as well as the bulk density of popped grains were calculated. The number of samples tested each time was five and the process was replicated twice and expressed as mean \pm SD. The popped grains were then ground in a laboratory model vertical grinder to obtain flour that passed through a BSS 60 mesh with an opening of 250 micron. The temperature of the sample was always kept below $40^{\circ} \mathrm{C}$ during grinding by cooling the samples as well as the grinder.

\section{Pigeon pea}

Grains were soaked in water for $24 \mathrm{~h}$. After decanting excess water, the grains were wrapped with gunny cloth and left for $36 \mathrm{~h}$ to germinate. Germinated grains were kilned at $105-110^{\circ} \mathrm{C}$ and were milled by a pulse dehusker (Ramakrishnaiah et al., 1999). It works on the principle of the dry milling technique by applying oil and heat treatment to the pulse followed by dehulling in an abrasive type unit. The dehusked kernels were then ground in the laboratory model vertical grinder to obtain flour that passed through a BSS 60 mesh.

\section{Soybean}

Soybean grains were decorticated using pulse dehusker (Ramakrishnaiah et al., 1999) and the kernels were soaked in water at room temperature $\left(28^{\circ} \mathrm{C}\right)$ for $4 \mathrm{~h}$. After draining excess water and drying surface moisture, the kernels were toasted at $200^{\circ} \mathrm{C}$ for 20 min and then ground in the laboratory model vertical grinder to obtain flour that passed through a BSS 60 mesh.

\section{Finger millet}

Finger millet grains were cleaned and soaked in water for $12 \mathrm{~h}$. Excess water was decanted, and soaked grains were wrapped in gunny cloth and left for germination for two days. Water was sprinkled during germination to keep grains moist. Sprouted grains were kilned, rootlets were removed, decorticated and powdered as indicated by Shobana and Malleshi (2007).

\section{Complementary food formulation}

The proportion of the main ingredients (processed sorghum, pigeon pea and soybean) was determined mainly based on proximate composition as recommended by Malleshi (1995). Accordingly, the complementary food was formulated using processed sorghum, pigeon pea, soybean, skimmed milk and sucrose in the ratio of 65:15:10:5:5 and blend was mixed thoroughly until uniform distribution of particles was obtained. The formulated complementary food (95 parts) was mixed with finger millet malt (5 parts) to prepare the product. Flow chart for preparation of the formulated complementary food is presented in Figure 1.

\section{Functional properties}

Swelling and solubility studies of the complementary food and ingredients were conducted at 30,55 and $95^{\circ} \mathrm{C}$. Swelling volume was determined according to the method of Crosbie et al. (1992). Flour samples $(0.4 \mathrm{~g}$, dry basis, $\mathrm{db}$ ) were mixed with $12.5 \mathrm{ml}$ of water, equilibrated at the respective temperature for $5 \mathrm{~min}$ and then centrifuged at $5000 \mathrm{rpm}$ for $15 \mathrm{~min}$. The swelling volume was calculated by converting the height of the resultant gels to a volume basis, and the results were reported as $\mathrm{g} / \mathrm{g}$ of dry flour. The supernatant was carefully removed and the difference of the initial and final volume due to swelling was observed for measuring solubility and expressed per gram of the initial weight of the dry flour. All experiments were repeated three times and values are presented as the mean of the three observations.

Viscosities of unprocessed and processed ingredients, as well as the complementary food formulation were measured using Brookfield viscometer. A known quantity of the respective flours was reconstituted in water at different solid concentrations ranging from 8 to $30 \%$ depending on experimental observation of the viscosity of individual test material. The slurry was heated in boiling water bath 


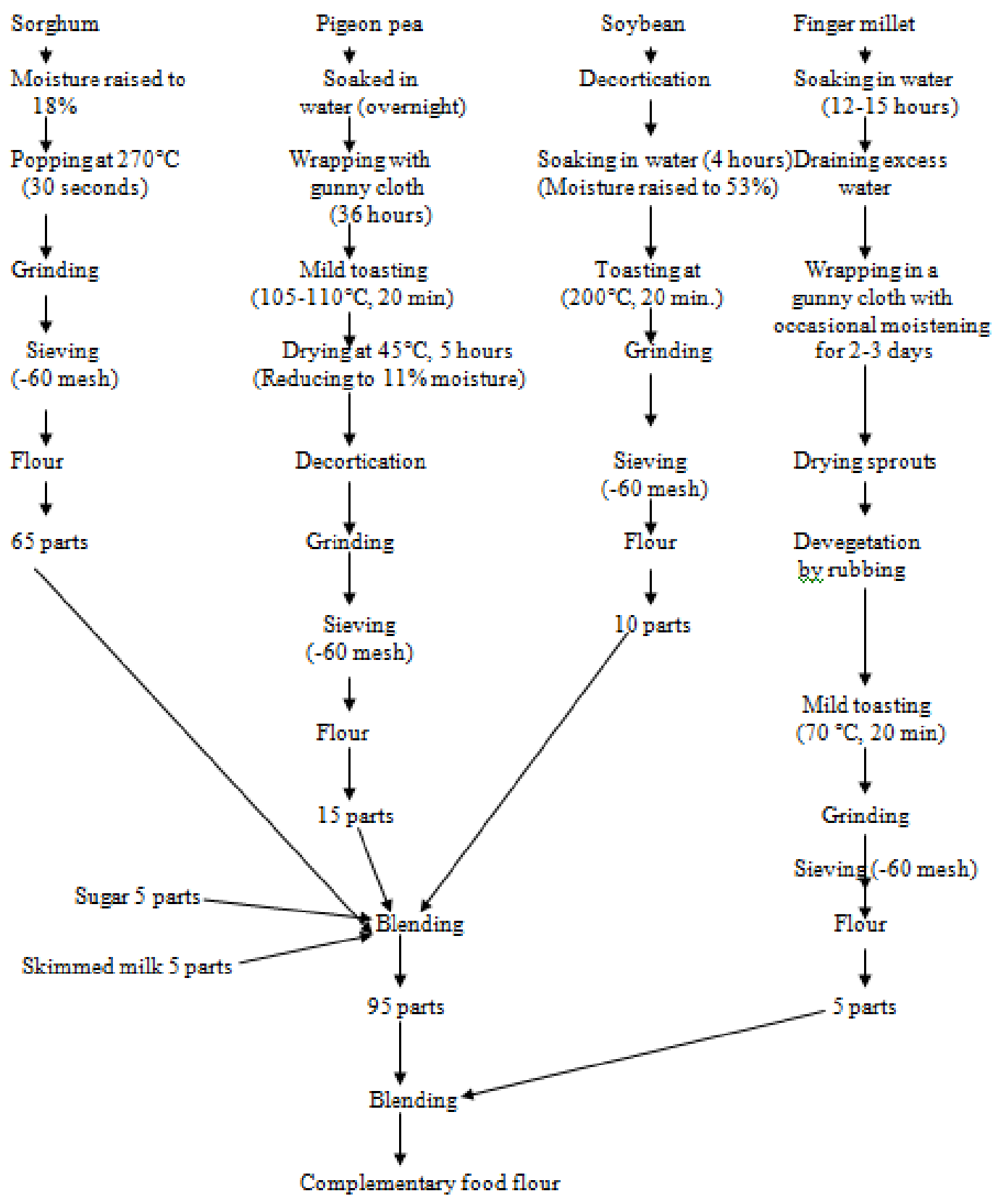

Figure 1. Flow chart for preparation of the formulated complementary food.

maintained at $95^{\circ} \mathrm{C}$ for 20 min with occasional stirring maintaining constant volume. The slurry was then cooled to ambient temperature and the viscosity was measured. A comparative viscosity study of processed and respective raw ingredients was also performed. The formulated complementary food with different percentage $(0,1$, $2,3,4,4.5$ and $5 \%$, w/v) of finger millet malt flour was also studied similarly to achieve the desired viscosity of the product.

Viscography of the complementary food and raw mix of the ingredients was also carried out following the method of Halick and Kelly (1959) and Kho and Singh (2009) by employing a Brabender visco-amylograph (Type VSK 4, Duisburg, FRG fitted with a 700cmg sensitivity cartridge) using a dispersion containing $15 \%$ flour solids $(\mathrm{db})$. The sample was heated up to $95^{\circ} \mathrm{C}$ at the rate of $1.5^{\circ} \mathrm{C} / \mathrm{min}$, held at $95^{\circ} \mathrm{C}$ for $20 \mathrm{~min}$ and cooled at $1.5^{\circ} \mathrm{C} / \mathrm{min}$ to $50^{\circ} \mathrm{C}$. Duplicate runs were made for each sample.

\section{Nutrient composition and digestibility study}

Moisture, ash, fat, crude protein and minerals, viz. calcium, iron, magnesium, zinc and copper were estimated using AOAC (2000) methods. Starch was determined following Chitra et al. (2010). Five grams (dry matter basis) of sample was boiled with $50 \mathrm{ml}$ of $1.124 \%$ $\mathrm{HCl}$ in a boiling water bath for $15 \mathrm{~min}$. The aliquot was transferred into a $100 \mathrm{ml}$ volumetric flask and cooled. Three milliliters each of $15 \%$ potassium ferrocyanide and $30 \%$ zinc sulfate were added into the digested samples and incubated at $20^{\circ} \mathrm{C}$ and polarimetric readings were taken on the same day. Starch content was then calculated using the following equation.

$\operatorname{Starch}(\%, d b)=\frac{\text { Observed reading } X 100}{185.7 \times 0.1 \text { Weight in } g, d m b} \times 100$ 
The results were expressed after applying a correction factor of $2.4 \%$ (adding to each value), which was necessitated as the starch recovery using the polarographic method slightly varies from one source to the other with a mean reduction of $2.4 \%$, db (Chitra et al., 2010). The complementary food was also analysed for amino acids (Bidlingmeyer et al., 1987), insoluble and soluble dietary fiber (Asp et al., 1983). In vitro protein and carbohydrate digestibility of the complementary food were also determined following the method of Walter and Mark (1964). Trypsin inhibitor activity (TIA) was estimated following Hamerstrand et al. (1981).

\section{Sensory evaluation}

Complementary food in powder form was dispersed in warm water $\left(50^{\circ} \mathrm{C}\right)$ at $10 \%$, and mixed well so that no lumps were present. The dispersion was boiled for 2 min and served in glass containers coded with 3-digit random numbers to minimize bias. The temperature of the sample at the time of serving to panelists was 50 to $55^{\circ} \mathrm{C}$.

Sensory evaluation of the complementary food was carried out in two stages by a trained panel of 10 assessors, in sensory booths maintained at $22 \pm 2{ }^{\circ} \mathrm{C}, \mathrm{RH} 50 \pm 5 \%$, under white fluorescent light. In the first stage of evaluation, "Free Choice Profiling" was used for formulating a suitable scorecard. This included listing of appropriate terminology describing individual quality attributes of the sample. Panelists were adequately trained to detect subtle differences in the perceived intensity of attributes and also to describe them. In the second stage, the "Quantitative Descriptive Analysis" method was employed for sensory analysis of the product. A $15 \mathrm{~cm}$ scale anchored at $1.25 \mathrm{~cm}$ on either end, representing "Recognition threshold" and "Saturation threshold," respectively was used for this purpose. Panelists were asked to mark on this scale to indicate the perceived intensity of each attribute. The scores for all the attributes were tabulated and the mean value was then taken for each attribute. These mean scores represented the panel's judgment about the sensory quality of the sample.

\section{Statistical analysis}

Descriptive statistical analysis was conducted using Microsoft $\AA$ Excel 2003 and the results were expressed as mean \pm SD whenever required.

\section{RESULTS AND DISCUSSION}

\section{Physicochemical properties of processed grains}

\section{Effect of moisture on physical properties of sorghum}

Popping of sorghum reduced bulk density from 753 to 89 $\mathrm{kg} / \mathrm{m}^{3}$. Increasing moisture content from the 11.3 to $18 \%$ further reduced bulk density of popped sorghum from 89 to $66 \mathrm{~kg} / \mathrm{m}^{3}$. Popping expanded the raw sorghum to $574 \%$, which was further improved to $767 \%$ by increasing the moisture content to $18 \%$. When moisture content of grains was further increased to about $20 \%$, the grain bulk density and percent expansion was decreased. Therefore, $18 \%$ moisture content was used for popping of sorghum. Higher expansion of popped grains is desirable because of enhanced food quality and also textural and economic benefits.

\section{Viscosity}

Viscosities of raw and processed flours of sorghum, pigeon pea and soybean are presented in Figure 2. The viscosity of processed flour varied considerably; at $10 \%$ slurry it was $2600 \mathrm{mPas}$ for sorghum, $863 \mathrm{mPas}$ for pigeon pea and was too thin for soybean to measure using the viscometer. It appears that the viscosity of the processed ingredients is highly positively correlated with the starch content of the flours. Up to $20 \%$ concentration soybean slurry was too thin and freely flowing. Sorghum at $15 \%$ concentration and pigeon pea at $20 \%$ concentration was too thick to measure the viscosity, while the viscosity of soybean at 25 and $30 \%$ concentration was only 737 and $3610 \mathrm{mPas}$, respectively.

Among the raw materials considered, sorghum showed highest viscosity at lower concentration (about 12 to $13 \%$ ) both in cooked raw and cooked processed materials as it contains highest amount of starch. The viscosity of cooked processed sorghum was lower than the cooked raw sorghum, which is an indication of the change in properties of cooked starch of the processed sorghum. Similar observation was also noticed in pigeon pea but at higher concentrations; 15 to $16 \%$ in cooked raw pigeon pea and about $18 \%$ in cooked processed pigeon pea. In the case of soybean, viscosity was registered at about $30 \%$ in cooked raw material and very high concentration in cooked processed material. In the processed soybean, denaturation of protein occurs but negligible amount of starch makes the cooked slurry to assume least viscosity even at higher concentrations.

\section{Solubility and swelling}

Table 1 shows solubility and swelling of the raw and processed flours of sorghum, pigeon pea and soybean at different temperatures. At lower temperature (pregelatinization temperature), all samples have relatively less solubility and swelling. In agreement with Muralikrishna et al. (1986), both solubility and swelling of processed samples were higher than raw flour samples at temperatures of 30 and $55^{\circ} \mathrm{C}$. While at cooking temperature $\left(95^{\circ} \mathrm{C}\right)$ both solubility and swelling were decreased due to equilibration. Among the samples, raw pigeon pea has the least water holding capacity at pregelatinization temperature. At gelatinization temperature, processed soybean has the lowest solubility and swelling. Higher solubility and swellling was observed for processed flours as compared to raw flour samples, which could partly be attributed to gelatinization of starch granules during popping, kilning and toasting of the grains. Similarly, increase in solubility of all the samples at the highest temperature could be partly attributed to gelatinization of starch during cooking, and relatively lower solubility of soybean could be due to its lower content of starch.

\section{Proximate composition and dietary fiber}

The proximate, soluble and insoluble dietary fiber content 


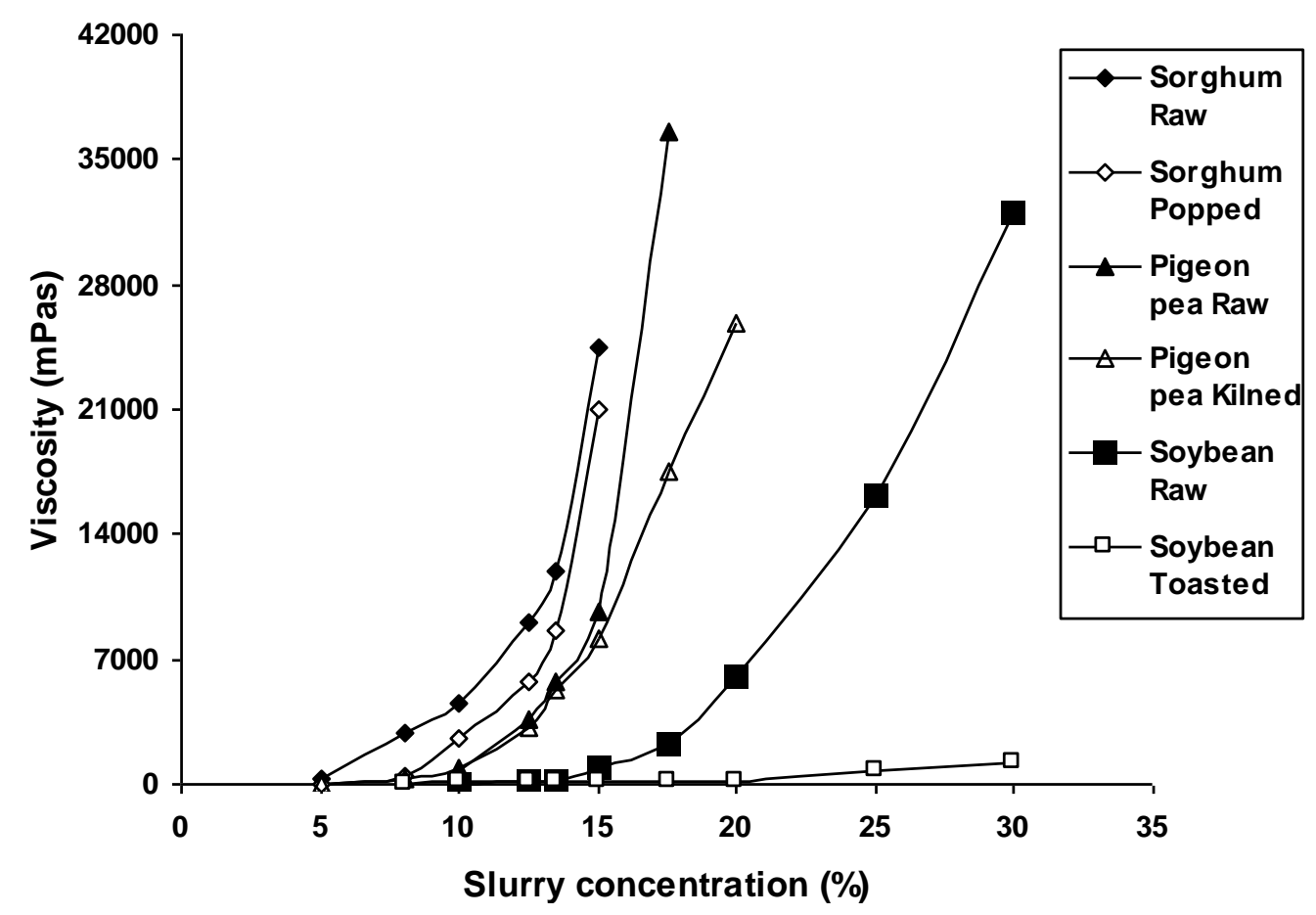

Figure 2. Viscosity of raw and processed ingredients.

Table 1. Solubility and swelling of raw and processed flours at different temperatures. Values are means of three independent measurements \pm SD.

\begin{tabular}{llccc}
\hline Test & Sample & $\mathbf{3 0}^{\circ} \mathbf{C}$ & $\mathbf{5 5 ^ { \circ } \mathbf { C }}$ & $\mathbf{9 5 ^ { \circ } \mathbf { C }}$ \\
\hline & Raw sorghum & $1.1 \pm 0.1$ & $1.8 \pm 0.0$ & $5.7 \pm 0.1$ \\
& Processed sorghum & $1.7 \pm 0.1$ & $2.8 \pm 0.0$ & $4.8 \pm 0.0$ \\
Solubility (g/g) & Raw pigeon pea & $1.1 \pm 0.4$ & $1.1 \pm 0.1$ & $4.9 \pm 0.1$ \\
& Processed pigeon pea & $1.5 \pm 0.0$ & $1.3 \pm 0.0$ & $4.6 \pm 0.0$ \\
& Raw soybean & $1.4 \pm 0.2$ & $1.1 \pm 0.1$ & $3.3 \pm 0.4$ \\
& Processed soybean & $1.5 \pm 0.0$ & $1.6 \pm 0.1$ & $2.8 \pm 0.2$ \\
& & & & \\
& Raw sorghum & $1.4 \pm 0.0$ & $1.8 \pm 0.1$ & $5.4 \pm 0.2$ \\
& Processed sorghum & $3.5 \pm 0.0$ & $2.6 \pm 0.3$ & $5.2 \pm 0.3$ \\
Swelling (g/g) & Raw pigeon pea & $0.8 \pm 0.0$ & $0.9 \pm 0.0$ & $4.8 \pm 0.0$ \\
& Processed pigeon pea & $1.4 \pm 0.1$ & $1.7 \pm 0.0$ & $4.3 \pm 0.0$ \\
& Raw soybean & $1.2 \pm 0.1$ & $1.3 \pm 0.2$ & $3.0 \pm 0.1$ \\
& Processed soybean & $1.5 \pm 0.1$ & $2.8 \pm 0.0$ & $2.6 \pm 0.1$ \\
\hline
\end{tabular}

of the ingredients of the complementary food is presented in Table 2. Raw sorghum contained the lowest quantity $(9.2 \%)$ of protein and soybean had the most $(41.7 \%, \mathrm{db})$. Protein content of pigeon pea increased from $22 \%$ in raw to $28 \%(\mathrm{db})$ in kilned sample which may be due to loss of moisture and leaching loss during germination. In soybean, decorticated samples contained the maximum protein level $(50 \%, \mathrm{db})$. As compared with sorghum and pigeon pea, soybean contained the least starch content $(6.3 \%$, db). Starch content was however reduced marginally by processing (popping, toasting and kilning). Breakdown of starch to lower molecular weight compounds might have brought marginal reduction during estimation.

Total dietary fiber content varied among the different flours and processing methods ranging from $6.3 \%$ in sorghum flour (raw) to $29.7 \%$ in soybean (toasted) on dry weight basis. The insoluble to soluble dietary fiber ratio was appreciably affected by popping (sorghum), germinated and kilning (pigeon pea) and toasting (soybean). In sorghum, the insoluble to soluble dietary fiber ratio 
Table 2. Nutritional composition and TIA of raw and processed flours ( $\mathrm{db}$ ). Values are means of three independent measurements \pm SD

\begin{tabular}{|c|c|c|c|c|c|c|c|c|}
\hline \multirow{2}{*}{ Sample } & \multirow{2}{*}{ Moisture (\%) } & \multirow{2}{*}{ Ash (\%) } & \multirow{2}{*}{ Fat (\%) } & \multirow{2}{*}{$\begin{array}{l}\text { Protein (protein } \\
\text { digestibility) (\%) }\end{array}$} & \multirow{2}{*}{$\begin{array}{c}\text { Starch (starch } \\
\text { digestibility) (\%) }\end{array}$} & \multicolumn{2}{|c|}{ Dietary fiber } & \multirow{2}{*}{ TIA (TIU/mg) } \\
\hline & & & & & & Insoluble (\%) & Soluble (\%) & \\
\hline Sorghum: raw flour & $14.8 \pm 0.0$ & $1.2 \pm 0.0$ & $3.3 \pm 0.0$ & $10.6 \pm 0.1(74.6)$ & $80.5 \pm 0.5(83.3)$ & $5.3 \pm 0.21$ & $1.0 \pm 0.4$ & $\mathrm{NC}$ \\
\hline Sorghum: popped & $9.8 \pm 0.1$ & $1.1 \pm 0.1$ & $4.6 \pm 0.4$ & $11.9 \pm 0.0(85.4)$ & $74.7 \pm 0.2(97.9)$ & $7.9 \pm 0.2$ & $1.0 \pm 0.3$ & $\mathrm{NC}$ \\
\hline Pigeon pea: raw flour & $8.6 \pm 0.4$ & $3.8 \pm 0.3$ & $1.8 \pm 0.2$ & $25.4 \pm 0.3(85.7)$ & $56.1 \pm 0.1(58.7)$ & $8.7 \pm 0.8$ & $3.4 \pm 0.1$ & 18.6 \\
\hline Pigeon pea: germinated and kilned & $7.3 \pm 0.2$ & $4.0 \pm 0.3$ & $2.8 \pm 0.0$ & $28.2 \pm 0.1(87.5)$ & $48.3 \pm 0.5(98.7)$ & $10.0 \pm 0.5$ & $1.3 \pm 0.2$ & 4.4 \\
\hline Soybean: raw & $11.0 \pm 0.1$ & $5.3 \pm 0.3$ & $23.0 \pm 0.1$ & $50.0 \pm 0.2(85.5)$ & $8.8 \pm 0.3(\mathrm{ND})$ & $19.7 \pm 2.0$ & $8.7 \pm 0.6$ & 88.6 \\
\hline Soybean: decorticated, toasted & $6.1 \pm 1.1$ & $6.1 \pm 0.1$ & $23.6 \pm 0.3$ & $48.1 \pm 0.4(88.6)$ & $6.0 \pm 0.1(\mathrm{ND})$ & $24.2 \pm 1.4$ & $5.5 \pm 0.1$ & 4.7 \\
\hline
\end{tabular}

$\mathrm{NC}=$ Analysis not conducted, and ND = composition not detected.

increased from 5.6:1 in raw flour to 8.1:1 of popped flour. Similarly, insoluble to soluble dietary fiber ratio increased from 2.5:1 to 7.9:1 in kilned and pulverized pigeon pea, and 2.3:1 to $4.5: 1$ in toasted soybean. The total dietary fiber content of each processed ingredient was higher than the raw material. Results of the present study are in close agreement with Azizah and Zainon (1997) who reported that most of the increment of dietary fiber during processing is due to insoluble fiber. According to Azizah and Zainon (1997), it is possible that thermal processing may cause production of Maillard reaction products and thus increase in the insoluble dietary fiber content. Increase in insoluble dietary fiber content by autoclaving and microwave treatment was also previously reported (Vidal-Valverde and Erias, 1991). Soluble dietary fiber mostly remained unchanged or reduced to some extent by processing. This is also in agreement with previous reports (Thed and Phillips, 1995; Azizah and Zainon, 1997).

\section{Protein and starch digestibility}

Popping of sorghum increased the starch digestibility from 83 (raw) to $98 \%$ due to gelatinization of starch during popping. Digestibility of starch in raw pigeon pea was relatively poor (59\%) but increased to $65 \%$ by germination and $99 \%$ by kilning (Table 2). Muralikrishna et al. (1986) and Mouliswar et al. (1993) have also observed that toasting increases digestibility of the starch.

Protein digestibility ranged from $75 \%$ in raw sorghum to $90 \%$ in germinated and decorticated pigeon pea. An increase in the protein digestibility of sorghum by popping and pigeon pea by kilning was observed. Som et al. (1992) have reported that cooking increases digestibility of protein marginally.

\section{Antinutritional composition}

Maximum TIA was detected in raw soybean (88.6 $\mathrm{TIU} / \mathrm{mg}$ ). Following decortication and toasting, TIA was reduced to a safe level of $4.7 \mathrm{TIU} / \mathrm{mg}$ for soybean (Table 2). Trypsin inhibitor has been known to bind to dietary protein and inhibit its digestibility which in turn affects growth of experimental animals. Among cereals and pulses, soybean is reported to contain the maximum level of TIA. Numerous reports are available on the effect of processing on TIA. Heat treatment significantly reduces TIA. Destruction of TIA is accompanied by a concomitant increase in the nutritive value of protein and is well documented by Liener (1994).

\section{Quality evaluation of the complementary food}

Different indicators are used to evaluate the quality of complementary foods including physicochemical characteristics and sensory attributes.

\section{Nutrient composition}

Nutrient composition of the complementary food is presented in Table 3. The complementary food contained 4 fats and $16 \%$ protein $(\mathrm{db})$ which are within the recommended range for complementary food development (Malleshi, 1995). The total dietary fiber content was $12.8 \%(\mathrm{db})$, which was slightly higher than the recommended standard for complementary food development (Malleshi, 1995). The digestibility study showed complete digestion of starch and $90 \%$ of protein. Higher digestibility of both starch and protein is an important characteristic of complementary foods. TIA was only detected in very trace quantity $(2.7 \mathrm{TIU} / \mathrm{mg})$.

The amino acid profile of the complementary food as obtained during the present study is presented in Table 3. Theoretical values from literature (Gopalan et al., 1989) of the essential amino acids (\%) of the complementary food were also extrapolated from proportion of the ingredients 
Table 3. Proximate and other compositions of the complementary food.

\begin{tabular}{|c|c|}
\hline Composition/parameter & Value \\
\hline Moisture $(\%, \mathrm{db})$ & $8.4 \pm 0.3$ \\
\hline Ether extractives $(\%, d b)$ & $4.2 \pm 0.1$ \\
\hline Protein $(\%, \mathrm{db})$ & $16.1 \pm 0.3$ \\
\hline Digestible protein (\%, db) & $14.4 \pm 1.0$ \\
\hline \multicolumn{2}{|l|}{ Amino acid $(\mathrm{g} / 100 \mathrm{~g})$} \\
\hline$A s x^{*}$ & $7.38 \pm 0.17$ \\
\hline $\mathrm{Gl}^{* *}$ & $22.12 \pm 0.33$ \\
\hline Ser & $5.31 \pm 0.08$ \\
\hline Gly & $4.09 \pm 0.06$ \\
\hline His & $2.83 \pm 0.29$ \\
\hline Arg & $6.38 \pm 0.18$ \\
\hline Thr & $3.92 \pm 0.06$ \\
\hline Ala & $4.97 \pm 0.17$ \\
\hline Pro & $7.20 \pm 0.20$ \\
\hline Tyr & $3.17 \pm 0.02$ \\
\hline Val & $4.79 \pm 0.05$ \\
\hline Met & $0.54 \pm 0.04$ \\
\hline Cys & $0.55 \pm 0.06$ \\
\hline Ile & $3.34 \pm 0.14$ \\
\hline Leu & $10.80 \pm 0.41$ \\
\hline Phe & $6.56 \pm 0.15$ \\
\hline Lys & $6.02 \pm 0.12$ \\
\hline Starch $(\%, \mathrm{db})$ & $59.6 \pm 0.3$ \\
\hline Digestible starch $(\%, \mathrm{db})$ & $59.0 \pm 0.8$ \\
\hline Insoluble dietary fiber $(\%, \mathrm{db})$ & $8.2 \pm 0.2$ \\
\hline Soluble dietary fiber $(\%, \mathrm{db})$ & $4.6 \pm 1.0$ \\
\hline Ash $(\%, d b)$ & $2.4 \pm 0.0$ \\
\hline Calcium $(\mathrm{mg} / 100 \mathrm{~g}, \mathrm{db})$ & $145.2 \pm 3.2$ \\
\hline Magnesium (mg/100 g, db) & $94.5 \pm 0.02$ \\
\hline Iron $(\mathrm{mg} / 100 \mathrm{~g}, \mathrm{db})$ & $6.0 \pm 0.03$ \\
\hline Zinc $(m g / 100 \mathrm{~g}, \mathrm{db})$ & $2.0 \pm 0.03$ \\
\hline Copper $(\mathrm{mg} / 100 \mathrm{~g}, \mathrm{db})$ & $0.47 \pm 0.08$ \\
\hline Trypsin inhibitor activity (TIU/mg) & $2.7 \pm 0.1$ \\
\hline \multicolumn{2}{|l|}{ Solubility $(\mathbf{g} / \mathbf{g})$} \\
\hline $30^{\circ} \mathrm{C}$ & $1.4 \pm 0.2$ \\
\hline $55^{\circ} \mathrm{C}$ & $1.1 \pm 0.1$ \\
\hline $95^{\circ} \mathrm{C}$ & $3.0 \pm 0.4$ \\
\hline \multicolumn{2}{|l|}{ Swelling $(g / g)$} \\
\hline $30^{\circ} \mathrm{C}$ & $1.2 \pm 0.1$ \\
\hline $55^{\circ} \mathrm{C}$ & $1.1 \pm 0.0$ \\
\hline $95^{\circ} \mathrm{C}$ & $2.6 \pm 0.3$ \\
\hline
\end{tabular}

Values are means of three independent measurements $\pm S D$; * Asx represents both Asp and Asn, ${ }^{* *}$ Glx represents both Gln and Glu.

(dry matter basis) in the complementary food to compare with the experimental results. Based on protein digestibility of the complementary food $(89.71 \%)$, protein digestibility corrected amino acid score (PDCAAS) of the experimental and theoretical values were calculated and found closely similar and in very good agreement with
$\mathrm{FAO} / \mathrm{WHO} / \mathrm{UNU}$ (1985) reference values (Table 4). $\mathrm{FAO} / \mathrm{WHO} / \mathrm{UNU}$ (1985) protein standard is an internationally accepted quality parameter for complementary food development. When the formulated complementary food is viewed in reference to the set standard, it appears comparable for 2 to 5 year old children. The developed complementary food also contained appreciable amount of minerals like calcium (145 mg/100 g) and magnesium $(95 \mathrm{mg} / 100 \mathrm{~g})$. However, it should be noted that phytic acid chelates with divalent metals including calcium, iron, magnesium and zinc thereby reducing bioavailability of the minerals (Liener, 1994). Effort should therefore be made to quantify and reduce the level of phytic acid in the complementary food as suggested by Liener (1994).

\section{Viscosity}

The cooked complementary food flour slurry exhibited high viscosity (Figure $3 \mathrm{~A}$ ) at $6 \%$ and above. This limits food intake by the child. Therefore, it was desirable to reduce the bulk in order to increase calorie and nutrient density of the complementary food. This was possible by adding 5\% finger millet malt flour (Figure 3B). When the complementary food containing $5 \%$ malt was cooked, the viscosity was reduced with appreciable quantity even at $20 \%$ concentration (Figure 3B) because of partial hydrolysis of starch and reduction in its water holding capacity. The viscosity of $20 \%$ cooked food was reduced from 23733 to $450 \mathrm{mPas}$ by adding $5 \%$ malt. The trend is in agreement with a previous report on complementary food (Malleshi et al., 1986). Malted complementary flour is rich in a-amylase. During cooking, alpha-amylase in the malt hydrolyzes the 1,4 $\alpha$-D-glucosidic linkages of polysaccharides. Starch is therefore degraded to lower molecular weight dextrins by the enzyme, and thus, viscosity of the heated paste decreases (Pertin, 1964; Dogan, 2002). Moreover, the enzyme $\alpha$-amylase is moderately stable to heat. During the heating phase (in the presence of moisture), $\alpha$-amylase gets activated and liquefies starches.

Using a Brabender Viscograph, the change in pasting characteristics of the mix of raw materials (without malt) and the cooked complementary food was studied (Figure 4). The viscogram mainly indicates the behavior of starch present in the raw materials and complementary food. The curve of the raw materials was initially parallel to the $X$-axis. With increasing temperature, the swelling increased and the food completely gelatinized at $74.2^{\circ} \mathrm{C}$. Peak viscosity (PV) and hot paste viscosity (HPV) were at 850 and $610 \mathrm{BU}$, respectively. At cooling temperatures of 50 and $30^{\circ} \mathrm{C}$, the viscosity was about 1500 and $1750 \mathrm{BU}$ (cold viscosity, CV), respectively, which is an indication of retrogradation or precipitation of linear molecules. The calculated set back viscosity (difference between CV and PV) was $900 \mathrm{BU}$ and total set back viscosity was 1140 $\mathrm{BU}$ (Figure 4) which is due to retrogradation of linear molecules in the starch granule.

Figure 4 shows the paste viscosity profile of the formulated food at $15 \%$ slurry concentration. Since the materials 
Table 4. Protein digestibility corrected amino acid score (PDCAAS) of formulated complementary food.

\begin{tabular}{|c|c|c|c|c|c|c|c|}
\hline Composition & $\begin{array}{c}\text { AA } \\
(\mathrm{mg} / \mathrm{g})^{\star}\end{array}$ & $\begin{array}{c}\text { AA } \\
(\mathrm{mg} / \mathrm{g})^{\star \star}\end{array}$ & $\begin{array}{l}\text { Reference } \\
\text { pattern }^{\star \star \star}\end{array}$ & $\begin{array}{c}\text { Digestibility } \\
\text { (AA x 89.4\%)* }^{*}\end{array}$ & PDCAAS* & $\begin{array}{c}\text { Digestibility } \\
(\mathrm{AA} \times 89.4 \%)^{\star \star}\end{array}$ & PDCAAS ${ }^{\star *}$ \\
\hline Histidine & 31.2 & 28.7 & 19 & 27.89 & 1.47 & 25.66 & 1.35 \\
\hline Lysine & 60.2 & 60.9 & 58 & 53.82 & 0.93 & 54.44 & 0.94 \\
\hline Tryptophan & 12.5 & ND & 11 & 11.18 & 1.02 & ND & - \\
\hline Phenylalanine + Tyrosine & 85.5 & 98.9 & 63 & 76.44 & 1.21 & 88.42 & 1.4 \\
\hline Methionine + Cystine & 31.2 & 11.1 & 25 & 27.89 & 1.12 & $\mathrm{NCQ}$ & - \\
\hline Threonine & 40.1 & 39.7 & 34 & 35.85 & 1.05 & 35.49 & 1.04 \\
\hline Leucine & 113.3 & 109.5 & 66 & 101.29 & 1.53 & 97.89 & 1.48 \\
\hline Isoleucine & 51.7 & 33.8 & 28 & 46.22 & 1.65 & 30.22 & 1.08 \\
\hline Valine & 58.7 & 48.6 & 35 & 52.48 & 1.50 & 43.45 & 1.24 \\
\hline
\end{tabular}

$\mathrm{AA}=$ Amino acid; ${ }^{*}=$ theoretical value; ${ }^{* *}=$ experimental value; ${ }^{* * *}=\mathrm{FAO} / \mathrm{WHO} / \mathrm{UNU}(1985)$ reference pattern (mg/g); Experimental value of protein digestibility (89.4\%) was used to calculate PDCAAS; ND = not detected; NCQ = not completely quantified due to degradation during hydrolysis.

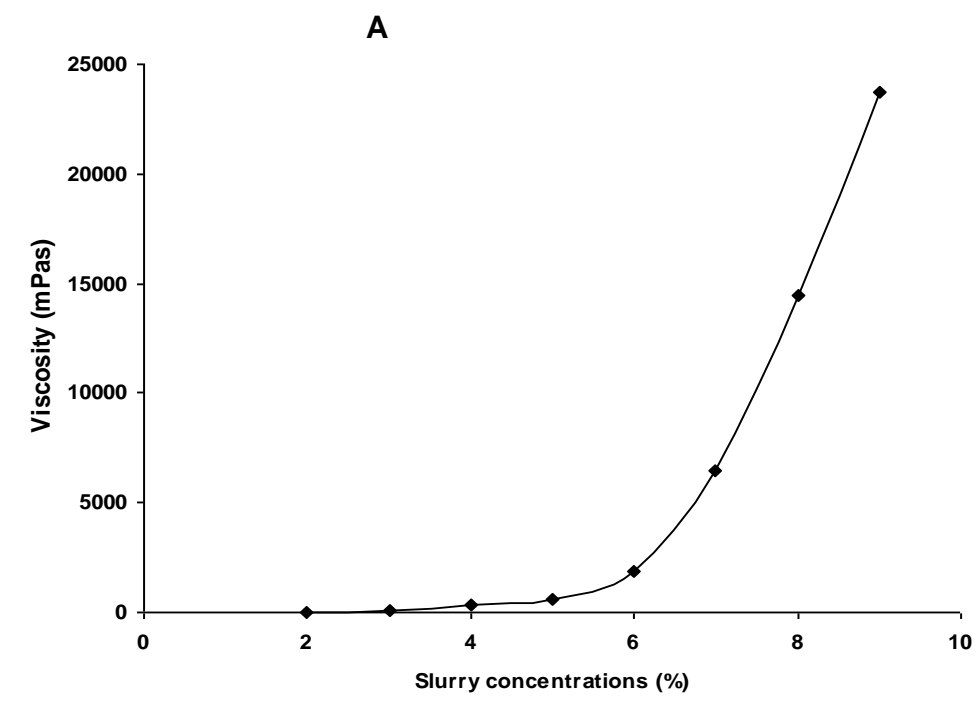

B

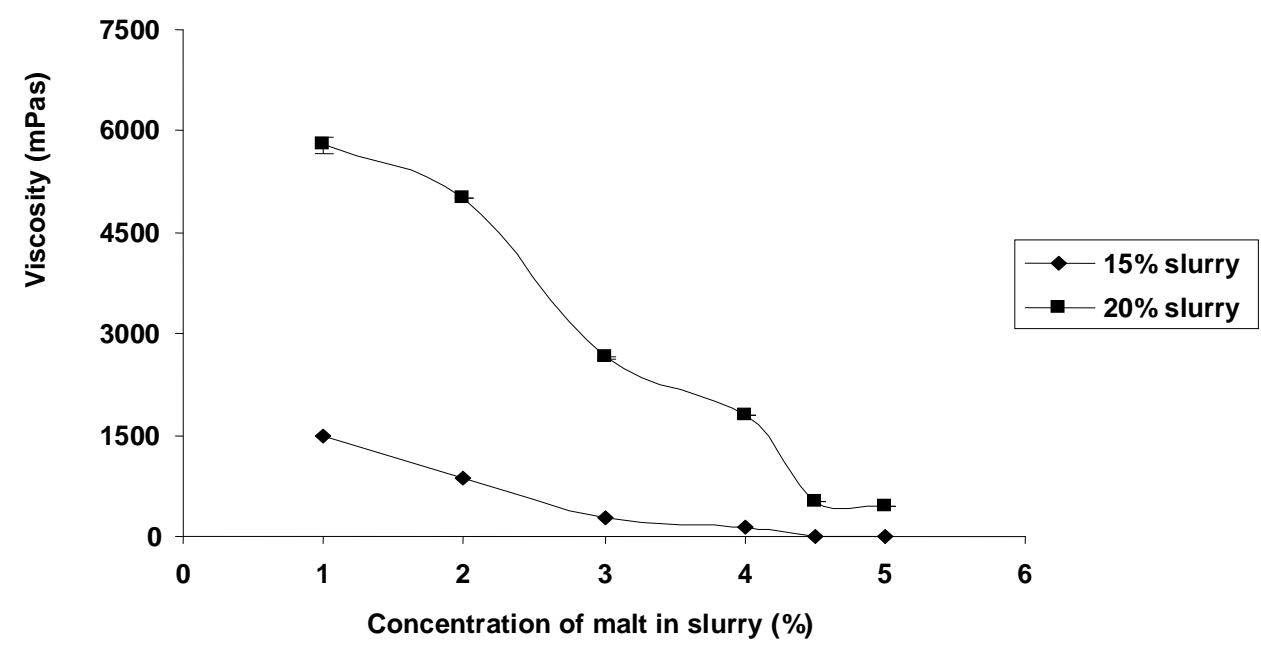

Figure 3. Effect of malt on viscosity of complementary food. A: Viscosity of complementary food without malt at different concentrations, B: Effect of malted finger millet on viscosity of complementary food at different slurry concentrations. 


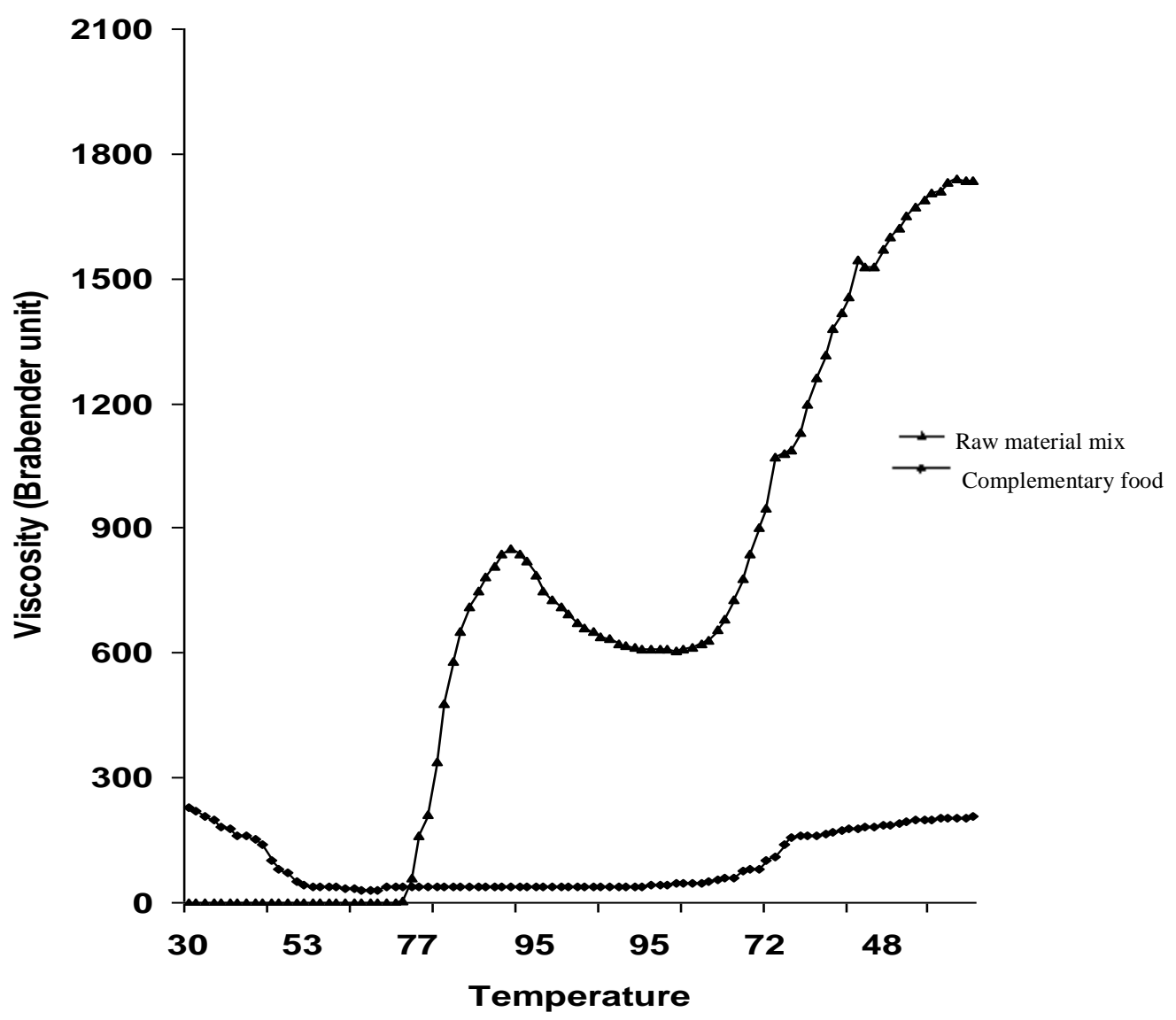

Figure 4. Paste viscosity profile of raw mix of the ingredients and formulated complementary food.

were precooked, the complementary food absorbed water soon after soaking and showed an initially higher viscosity value. During cooking temperature $\left(95^{\circ} \mathrm{C}\right)$ in particular, the complementary food had extremely low viscosity and was a free flowing fluid. At cooling temperature $\left(30^{\circ} \mathrm{C}\right)$, the consistency remained thin and showed a slight increase in viscosity. This is in contrast with the viscosity profile of the raw material which formed a thick gel that would probably be impossible for an infant to swallow. Previous investigators (Malleshi and Desikachar, 1988) also observed a lower viscosity of malted complementary food as compared with roller dried proprietary complementary food (PWF). The comparative study of malted complementary food (MWF) with proprietary complementary food (PWF) showed that MWF had considerably less viscosity than PWF. According to these investigators, for a comparable slurry viscosity of 55 $\mathrm{mPas}$, the MWF had 50 to $100 \%$ more calories as compared to different proprietary complementary foods paste viscosity. Reduced viscosity would enable the child to take more of the product per feed or higher nutrient and calorie dense complementary food at a time. Malleshi et al. (1986) indicated that this kind of complementary food is superior over complementary foods developed by modern technologies such as roller drying.

\section{Swelling and solubility}

Severity of heat treatment during popping might cause structural changes in starch and protein resulting in increased water absorption. Although higher water absorption is desirable in some food preparations such as bakery, this 'bulking' property is disadvantageous for complementary foods where low 'dietary bulk' is desired. In the present study, the problem was solved to an appreciable extent by adding $5 \%$ of finger millet malt flour. The solubility and swelling of the formulated complementary food at three temperatures is presented in Table 3. Gelatinization temperature increased solubility and swelling of the formulated complementary food as compared to pregelatinization temperature. Unlike sorghum and pigeon pea, the complementary food has relatively less solubility and swelling, which could be attributed to the presence of sucrose, milk and malt. One of the important qualities of a complementary food is its water holding capacity. Since water does not have any calorific value, an increase in its level will reduce energy value of the product. Therefore, low water holding capacity is a desirable characteristic of 


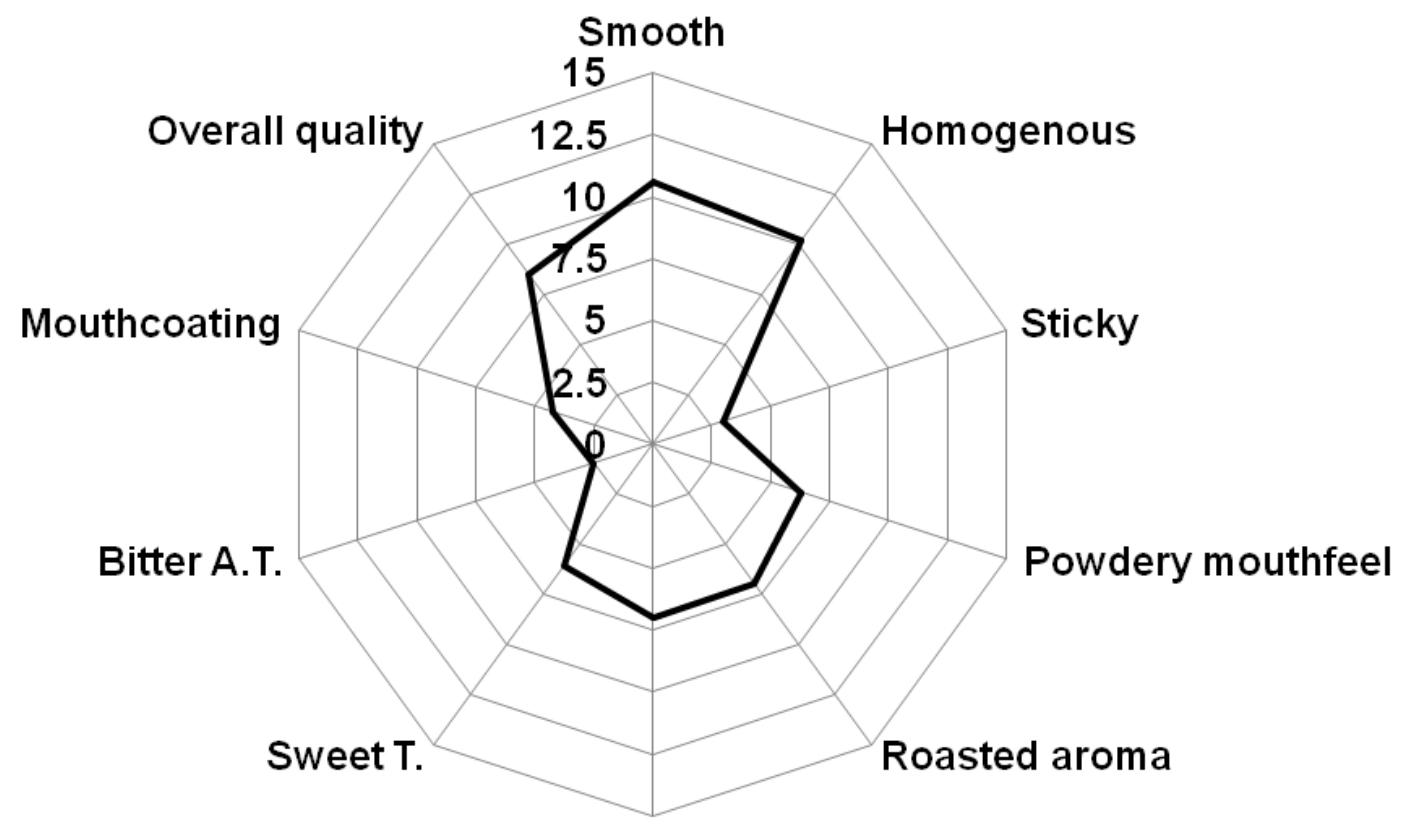

Husklike aroma

Figure 5. Sensory profile of the complementary food.

the complementary food.

\section{Sensory evaluation}

Mean scores for sensory evaluation of each attribute of the sample are graphically presented as "sensory profile" in Figure 5. It was observed that the complementary food in powder form could be easily dispersed in warm water without any lumps. The complementary food preparation was smooth and homogeneous, without any noticeable stickiness. This is a desirable property, which facilitates easy swallowing of the food by the infants, the target group for which the product has been developed. Roasted aroma and husk-like aroma were perceived by most of the panelists. Sweet taste was perceived to be at a desirable level. Overall quality was fairly high which aptly reflected the acceptability of the complementary food preparation.

\section{Conclusions}

Important aspects of complementary food formulation were studied including physical properties, quantity and quality of nutrients, antinutritional factors and sensory evaluation. In vivo protein bioavailability, important nutrients such as vitamins, storage and packaging characteristics await further study. The formulated complementary food can however be produced by small and large scale industries and used at the local level to alleviate child malnutrition. Depending upon the requirements, operating capacity and corresponding degree of mechanization, the scale of production canvary to suit the local needs and conditions. To produce a complementary food at industrial level, further fortification with required quality and quantity of micronutrients (premix) is required.

\section{REFERENCES}

AOAC (2000). Official methods of the AOAC International. Determination of lead, cadmium, and minerals in foods by Atomic Absorption spectrophotometry (method 999.11/985.35). Association of Official Analytical Chemists, Gaithersburg, USA.

Asma MA, Fadil EBE, Tinay AHE (2006). Development of weaning food from sorghum supplemented with legumes and oil seeds. Food Nutr. Bull. 27(1): 26-34.

Asp N-G, Johansson C-G, Hallmer H, Siljeström M (1983). Rapid enzymatic assay of insoluble and soluble dietary fiber. J. Agric. Food Chem. 31: 476-482.

Azizah AH, Zainon $\mathrm{H}$ (1997). Effect of processing on dietary fiber contents of selected legumes and cereals. Malaysian J. Nutr. 3: 131136.

Bidlingmeyer BA, Cohen SA, Tarvin TL, Frost B (1987). A new, rapid, high-sensitivity analysis of amino acids in food type samples. J. Assoc. Anal. Chem. 70(2): 241-247.

Central Statistical Agency (Ethiopia) and ORC Macro (2006). Ethiopia Demographic and Health Survey 2005, Central Statistical Agency and ORC Macro, Addis Ababa, Maryland, p. 474.

Chitra C, Singh V, Ali SZ (2010). Effect of processing paddy on digestibility of rice starch by in vitro studies. J. Food Sci. Technol. 47(4): 414-419.

Crosbie GB, Lambe WJ, Tsutsui H, Gilmour RF (1992). Further evaluation of the flour swelling volume test for identifying wheats potentially suitable for Japanese noodles. J. Cereal Sci. 15: 271-280.

de Onis M, Monteiro C, Akr J, Clugston G (1997).The Worldwide magnitude of protein-energy malnutrition: An Overview from the WHO Global Database on Child Growth. WHO, Geneva, Switzerland.

Dogan IS (2002). Dynamic rheological properties of dough as affected by amylases from various sources. Nahrung 46: 399-403.

FAO/WHO/UNU (1985). Energy and protein requirements. WHO technical report series 724. WHO, Geneva, Switzerland. p. 209. 
Getahun Z, Urga K, Ganebo T, Nigatu A (2001). Review of the status of malnutrition and trends in Ethiopia. Ethiop. J. Health Dev. 15(2): 5574.

Gopalan C, Sastri BVR, Balasubramanian SC (1989). Nutritive value of Indian foods, National Institute of Nutrition, Indian Council of Medical Research, Hydrabad. p. 161.

Government of the Federal Democratic of Ethiopia (2008). Program Implementation Manual of National Nutrition Program (NNP) - I: June 2008 - June 2013. Federal Ministry of Health, Addis Ababa, Ethiopia. p. 128.

Halick JV, Kelly VJ (1959). Gelatinization and pasting characteristics of rice varieties as related to cooking behavior. Cereal Chem. 36(1): 91 98.

Hamerstrand GE, Black LT, Glover JD (1981). Trypsin inhibitors in soy products: Modifications of the standard analytical procedure. Cereal Chem. 58(1): 42-45.

Koh BK, Singh V (2009). Cooking behaviour of rice and black gram in the preparation of Idli, a fermented product of South Indian Origin by Viscography. J. Texture Stu. 40: $36-50$.

Liener IE (1994). Implications of nutritional components in soybean foods. Crit. Rev. Food Sci. Nutr. 34(1): 31-67.

Malleshi NG (1995). Weaning foods. Regional extension, service centre (rice milling), ministry of food processing industries, government of India. RESC Scientific Series. Central Food and Technological Research Institute, Mysore, India. pp. 8: 50.

Malleshi NGM, Desikachar HSR (1988). Reducing the paste viscosity (dietary bulk) of roller dried weaning foods using malt flour or fungal amylase. J. Food Sci. Technol. 25: 1-3.

Malleshi NGM, Rao SNR, Sreedharamurty S, Desikachar HSR (1986). Development of weaning foods based on some traditional technologies. J. Food Sci. Technol. 23: 315-318.

Mouliswar P, Kurien S, Daniel VA, Malleshi NG, Rao SV (1993). In Vitro digestibility of protein and starch energy food and its bulk reduction. J. Food Sci. Technol. 30(1): 36-39.
Muralikrishna G, Malleshi NG, Desikachar HSR, Tharanathan RN (1986). Effect of popping on the properties of some millet starches. Starch/stärke 38: 48-51.

Pertin H (1964). Application of the Falling number method for evaluating a-amylase activity. Cereal Chem. 41: 127-140.

Ramakrishnaiah N, Pratape VM, Narasimha HV, Shangmugam GK (1999). An Improved Mechanised Pulse Dehusker. Indian Patent Application No. 2385/Del/98.

Shobana S, Malleshi NG (2007). Preparation and functional properties of decorticated finger millet (Eleusine coracana). J. Food Eng. 79: 529-538.

Som JN, Mouliswar P, Daniel VA, Malleshi NG, Rao SV (1992). Digestibility of protein and starch in malted weaning foods. J. Food Sci. Technol. 29(4): $262-263$.

Thathola A, Srivastava S (2002). Physicochemical properties and nutritional traits of millet-based weaning food suitable for infants of the Kumaon Hills, Northern India. Asia Pac. J. Clin. Nutr. Asia 11(1): 2832.

Thed ST, Phillips RD (1995). Changes of dietary fiber and starch composition of processed potato products during domestic cooking. Food Chem. 52: 301-304.

UNICEF (2009). Press release: UNICEF highlights child survival on the Day of African Child. http://www.unicef.org/media/media_50001.html. Accessed 28 July 2009.

Vidal-Valverde C, Erias J (1991). Legume processing effects on dietary fiber components. J. Food Sci. 56(5): 1350-1352.

Walter R, Mark AS (1964). A pepsin pancreatin digest index of protein quality evaluation. J. Nutr. 83: 257-261.

WHO (1998). Complementary feeding of young children in developing countries. WHO/NUT/98.1 WHO, Geneva, Switzerland. pp. 167-170.

WHO (2009). World Health Statistics. WHO, Geneva, Switzerland. p. 149 . 